\title{
Does CAD Improve Spatial Visualization Ability?
}

\author{
Jianping Yue \\ Department of Engineering Technologies \\ Essex County College \\ Newark, New Jersey \\ Daniel M. Chen \\ Department of Industrial and Engineering Technology \\ Central Michigan University \\ Mount Pleasant, Michigan
}

\begin{abstract}
This paper presents a study conducted collaboratively at a two-year community college and a four-year university. Technical drawing skills are fundamental to engineering technology students. It is generally believed that spatial visualization abilities affect a student's performance in graphics courses. Do factors, such as training, age, and gender, contribute to spatial visualization abilities? Do computer-aided design (CAD) courses improve spatial visualization abilities? This study investigates these factors through the Purdue Spatial Visualization Test Rotation. The statistical results, obtained from two different student populations representing two-year and four-year institutions, are compared. The results from the two-year college also supplement numerous studies done at other four-year universities.
\end{abstract}

\section{Introduction}

Since proficiency in engineering graphics is essential to engineering and technology students, the relationship between spatial visualization ability and technical drawing skills has long been an interesting research topic for engineering and technology educators. Does training improve spatial visualization ability? Research results have not been able to draw a definite conclusion. Some research results ${ }^{3,15}$ showed that graphics training did improve spatial visualization ability, while other studies ${ }^{7,13,14,17}$ showed no evidence of such improvement. Recent years, computeraided design (CAD) software packages have been widely used in engineering and technology

Proceedings of the 2001 American Society for Engineering Education Annual Conference \& Exposition

Copyright (C) 2001, American Society for Engineering Education 
curricula. A joint study was concurrently conducted at Essex County College and Central Michigan University to investigate whether or not CAD training improves spatial visualization ability. A comparative study was reported in two similar four-year universities ${ }^{6}$. This paper reports the comparative studies conducted at two different institutions, one an urban two-year community college and the other a rural four-year university. The results are compared to find if there is a difference between the two institutions. Other factors investigated include gender and age.

\section{The Spatial Visualization Test}

Various tests have been developed to measure different levels of spatial visualization ability ${ }^{1}$. Among these tests, the Purdue Spatial Visualization Test - Rotation (PSVT-R) ${ }^{9}$ has been widely used by researchers. This study also chose the PSVT-R to measure spatial visualization ability. The PSVT-R was designed to test rotational visualization ability. It consists of 30 multiplechoice problems. In each problem, an example first shows an object in its original and rotated views in isometric drawing. Then another object is shown in five different rotations, and the student is to choose the rotation that matches the given example. A sample problem similar to that of the PSVT-R is shown in Figure 1.

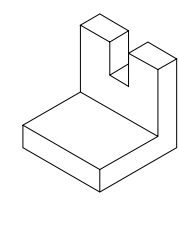

IS ROTATED TO
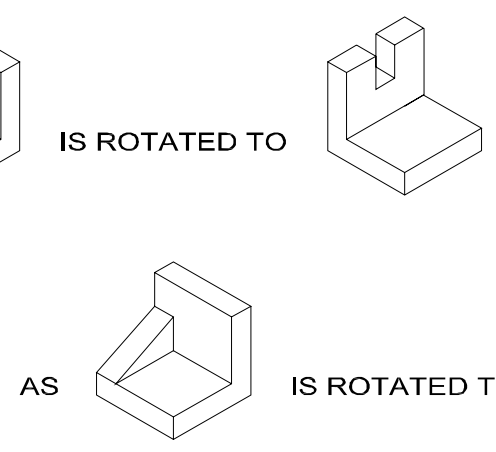

IS ROTATED TO
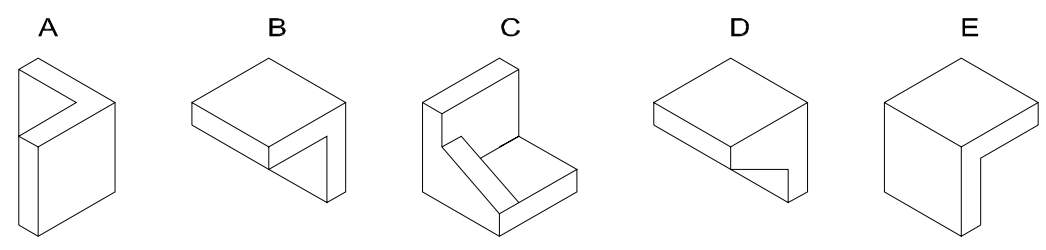

Figure 1. Example of a Rotational Spatial Visualization Problem ${ }^{17}$

Proceedings of the 2001 American Society for Engineering Education Annual Conference \& Exposition 
All of the 3D objects in the PSVT-R have simple geometric shapes of either a cube or a cylinder with cut slots. The rotations are combinations of $90^{\circ}$ and $180^{\circ}$ about the axes of the Cartesian coordinate system. The total of 30 problems in the PSVT-R can be categorized into 4 types according to the patterns of rotation (Table 1).

Table 1. Types of Rotations in the PSVT-R

\begin{tabular}{|l|l|l|}
\hline Type & Rotation & Number of Problems \\
\hline I & $90^{\circ}$ rotation about one axis & 6 \\
\hline II & $180^{\circ}$ rotation about one axis & 8 \\
\hline III & $\begin{array}{l}\text { One } 90^{\circ} \text { rotation about one axis and another } 90^{\circ} \text { rotation about } \\
\text { another axis }\end{array}$ & 8 \\
\hline IV & $\begin{array}{l}180^{\circ} \text { rotation about one axis and } 90^{\circ} \text { rotation about another } \\
\text { axis }\end{array}$ & 8 \\
\hline
\end{tabular}

As shown in Table 1, the degrees of difficulty of rotation increase from Type I through Type IV, and are also quite evenly distributed in the test. From test design point of view, the more difficult the rotations, the harder the visualization. Yue ${ }^{17}$ tested the validity of the PSVT-R by examining the relationship between the difficulty of rotations and the visualization test scores. Applying one-way analysis of variance (ANOVA) on 64 samples, he found that there are significant differences among the mean PSVT-R scores for the 4 types of rotations $[\mathrm{F}(3,252)=$ $11.38, \mathrm{p}<.01]$. Yue further analyzed, using the Scheffe's method, the mean score differences between every pair of the 4 types of rotations, namely $X_{1}-X_{2}, X_{1}-X_{3}, X_{1}-X_{4}, X_{2}-X_{3}, X_{2}-$ $\mathrm{X}_{4}$, and $\mathrm{X}_{3}-\mathrm{X}_{4}$, where $\mathrm{X}_{\mathrm{i}}$ is the mean score for Type $\mathrm{i}$. The results showed that the mean score differences are significant for $\mathrm{X}_{1}-\mathrm{X}_{2}$ and $\mathrm{X}_{1}-\mathrm{X}_{4}$, but not for other pairs. Therefore, the simplest single $90^{\circ}$ rotation is easier to visualize than other more difficult types of rotations, but the scores for the more difficult rotations are not statistically distinguishable. Further researches are needed to find whether this is a general pattern of visualization, or the PSVT-R, though a well designed visualization test, could be further improved.

\section{Test Samples}

Two groups of samples were used in this study. One group of samples was from Essex County College (ECC), and the other from Central Michigan University (CMU). ECC is a two-year urban community college located in the downtown of Newark, New Jersey. The 18 ECC student samples were from two CAD classes in the Department of Engineering Technologies: ENR 105 Applied CAD (2 semester credits and 3 contact hours) and ENR 205 Advanced CAD (3 semester credits and 3 contact hours). ENR 105 is a required freshman course for A.S. degree in engineering and A.A.S. degrees in architectural, civil/construction, manufacturing, and 
mechanical engineering technologies, as well as the CAD certificate. ENR 205 is a required sophomore course for the architectural technology degree and the CAD certificate program. In both classes, the students had already taken an engineering graphics course and used AutoCAD as a software package. CMU is a four-year university in Mount Pleasant, Michigan. The 24 CMU student samples were from IET 457 Computer-Aided Design ( 3 semester credits and 4 contact hours), a senior solid modeling class that uses SDRC/I-DEAS, and most had taken freshman General Drafting, Engineering Graphics, and junior level Computer-Aided Drafting courses. These students major in various programs including computer-integrated manufacturing, manufacturing engineering technology, mechanical engineering technology, industrial technology management with concentrations in mechanical design and engineering graphics, manufacturing production processes, construction technology, and automobile technology.

The PSVT-R test was given twice to both sample groups during the spring 2000 semester, one at the beginning of the semester (pre-test) and the other at the end of the semester (post-test). Then the results of the two tests were compared to investigate the effects of CAD training to visualization ability. Next, the results from the two institutions were also compared to reveal any variation between different college populations and CAD course levels.

Some students took the pre-test but not the post-test for various reasons such as dropping out of the class. Only those students who took both the pre-test and the post-test were included in this investigation.

\section{Test Results}

The statistical analyses of the results by the $t$ test (Student test) are as follows.

\subsection{CAD training and Spatial Visualization Ability}

For the 18 ECC students who took the pre-test and post-test of PSVT-R, the mean scores are respectively 22.67 and 22.94 out of 30 (or about $76 \%$ for both). There was no significant difference between the pre-test and post-test $[t(17)=0.31, p>.05]$.

For the $24 \mathrm{CMU}$ students, the mean scores of the pre-test and post-test are also very close (24.96 and 24.46 , or about $83 \%$ and $82 \%$ respectively.) There was also no significant difference between the pre-test and post-test $[t(23)=0.61, p>.05]$.

Therefore, the results of both groups of sample students showed that there is no evidence that CAD training improved spatial visualization ability.

When repeated tests are conducted, possible retest effect is always a concern. It is highly possible that the post-test scores could be higher than the pre-test scores. Obviously, the retest

Proceedings of the 2001 American Society for Engineering Education Annual Conference \& Exposition Copyright (C) 2001, American Society for Engineering Education 
effect did not occur in both groups. Interestingly, the CMU group's post-test mean score is even slightly lower than their pre-test mean score.

\subsection{Comparison of the Two Sample Groups}

Observing that the mean scores of the CMU group is higher than that of the ECC group (83\% vs. $76 \%$ ), we further compared the mean scores of the pre-tests at ECC and CMU. The difference in the mean scores is not statistically significant $[t(40)=1.53, p>.05]$.

The mean score differences could be contributed by many factors. The CMU group were juniors and seniors who had taken at least three engineering graphics and CAD courses, while the ECC group were freshman and sophomore students who had taken only one or two engineering graphics and CAD courses. More researches and evidences are needed to find if systematic training and comprehensive knowledge, rather than a single CAD course, are necessary to improve spatial visualization ability. Spatial visualization abilities may have been developed in more informal ways, such as childhood play with construction blocks, drafting experiences, computer games, and real-life experience with 3D objects.

\subsection{Gender and Spatial Visualization Ability}

Many studies have shown that gender is a factor in spatial visualization ability $2,8,10,11,12$. In spatial visualization tests, the mean scores of male students were generally higher than that of female students. The results of this study could not substantiate such a generalization as they did not show the effect of gender in spatial visualization ability.

There are 2 female students and 16 male students in the ECC group. The average pre-test scores of the PSVT-R were 22.00 and 22.75 for female and male students respectively. There was no significant difference between the female and male students $[t(16)=0.15, p>.05]$.

The result of the CMU was similar. The average pre-test scores of the PSVT-R were 26.20 for the 5 female students and 24.63 for the 19 male students respectively. The female students' score is slightly higher than that of the male students, but statistically there was no significant difference between the female and male students $[t(22)=1.06, p>.05]$.

\subsection{Age and Spatial Visualization Ability}

To investigate possible age factor in spatial visualization ability, we divided the students from ECC and CMU in two age groups, one under 23 years of age and the other 23 years of age or older. The mean pre-test scores of the PSVT-R of the younger groups were slightly higher than that of the older groups for both schools.

Proceedings of the 2001 American Society for Engineering Education Annual Conference \& Exposition Copyright (O) 2001, American Society for Engineering Education 
In the ECC group, there were 11 students younger than 23 and 7 students at 23 years of age or older. Their mean pre-test scores of the PSVT-R were 23.55 and 21.29 respectively. There was no significant difference between the two age groups $[t(16)=0.71, p>.05]$.

For the CMU students, 18 were younger than 23 and 6 were 23 years of age or older. The mean pre-test scores of the PSVT-R were 25.56 for the younger group of students and 23.17 for the older group. The mean score of the younger group was statistically slightly higher than that of the older group $[t(22)=1.80, p<.05]$.

\section{Conclusion}

To investigate the effect of CAD training on the improvement of spatial visualization abilities, the PSVT-R test was conducted concurrently to the engineering and technology students at both Essex County College and Central Michigan University during the spring 2000 semester. The study provided comparisons between two different student populations, one at a two-year community college and the other a four-year university.

Most of the results of statistical analyses were consistent for the two institutions, despite the difference of their student profiles. By comparing the pre-test and post-test scores of the PSVT$\mathrm{R}$ at the beginning and end of the semester in CAD classes, the authors found no significant evidence that $\mathrm{CAD}$ training improved visualization ability at both institutions. There was no significant difference between the mean PSVT-R scores of the female and male students at both institutions. For the two age groups, under 23 years of age and at 23 and older, the mean PSVTR scores were not significantly different at Essex County College, but slightly higher statistically for the younger students at Central Michigan University. These results, except the age factor showed by the Central Michigan University group, confirmed that of an earlier study by the author at $\mathrm{ECC}^{17}$.

The sample sizes in this study were small at both institutions (18 students at Essex County College and 24 students at Central Michigan University.) More investigations are under way using larger sample sizes. Further studies on spatial visualization ability include development and evaluation of new tests, investigation of other possible factors, and comparison of different institutions and student populations.

\section{Bibliography}

1. Baartmans, B. G. \& Sorby, S. A. (1996). Introduction to 3-D Spatial Visualization. Prentice Hall

2. Battista, M. T. (1980). Interrelationships between Problem Solving Ability, Right Hemisphere Processing Facility, and Mathematics Learning. Focus on Learning Problems in Mathematics, 2, 53-60 
3. Battista, M. T., Wheatley, G. H., \& Talsma, G. (1982). The Importance of Spatial Visualization and Cognitive Development for Geometry Learning in Preservice Elementary Teachers. Journal for Research in Mathematics Education, 13(5), 332-340

4. Branoff, T. J. (1998). The Effects of Adding Coordinate Axes to a Mental Rotations Task in Measuring Spatial Visualization Ability in Introductory Undergraduate Technical Graphics Courses. The Engineering Design Graphics Journal, 62(2), 16-34

5. Branoff, T. J. (1998). Coordinate Axes and Mental Rotation Tasks: A Dual-Coding Approach. 1998 ASEE Annual Conference Proceedings, Session 1248

6. Branoff, T. J., \& Connolly, P. E. (1999). The Addition of Coordinate Axes to the Purdue Spatial Visualization Test - Visualization of Rotations: A Study at Two Universities. 1999 ASEE Annual Conference Proceedings, Session 1438, June 20-23, Charlotte, North Carolina

7. Brinkman, E. H. (1966). Programmed Instruction as a Technique for Improving Spatial Visualization. Journal of Applied Psychology, 50, 179-184

8. Burnett, S. A., Lane, D. M., \& Dratt, L. (1979). Spatial Visualization and Sex Differences in Quantitative Ability. Intelligence, $\underline{3}, 345-354$

9. Guay, R. B. (1977). Purdue Spatial Visualization Test - Rotations. West Lafayette: Purdue Research Foundation

10. Guay, R. B. (1980). Spatial Ability Measurement: A Critique and an Alternative. A paper presented at the 1980 Annual Meeting of the American Educational Research Association, April, Boston, Massachusetts (ERIC Document Reproduction Service No. ED189166)

11. Harris, L. (1976). Sex Differences in Spatial Ability: Possible Environmental, Genetic, and Neurological Factors, In M. Kinsbourne (ed.), Hemispheric Asymmetries of Function, Cambridge: Cambridge University Press

12. Maccoby, E. E., \& Jacklin, C. N. (1974). The Psychology of Sex Differences. Stanford: Stanford University Press

13. Moses, B. E. (1977). The Nature of Spatial Ability and Its Relationship to Mathematical Problem Solving. Doctoral Dissertation, Indiana University

14. Nelson, G. T. (1974). The Effects of Diagram Drawing and Translation on Pupils' Mathematics Problem Solving Performance. Doctoral Dissertation, University of Iowa

15. Sorby, S. A., \& Baartmans, B. J. (1996). Improving the 3-D Spatial Visualization Skills of Women Engineering Students. 1996 ASEE Annual Conference Proceedings, Session 1692

16. Sorby, S. A. (1999), Spatial Abilities and Their Relationship to Computer Aided Design Instruction. 1999 ASEE

17. Yue, J. (2000), Spatial Visualization and Graphics Learning, Proceedings of the $4^{\text {th }}$ International Conference on Engineering Design and Automation, July 30-August 2, 2000, Orlando, Florida, pp. 56-61.

JIANPING YUE

Jianping Yue is an Assistant Professor and Coordinator of Manufacturing and Mechanical Engineering Technology at Essex County College, Newark, New Jersey. He is a Certified Senior Industrial Technologist by the National Association of Industrial Technology. Dr. Yue received his B.S. and M.S. degrees in Hydraulic and Coastal Engineering from Wuhan Institute of Hydraulic and Electric Engineering in Wuhan, China in 1977 and 1982, and a Ph.D. degree in Civil Engineering from Memphis State University, Memphis, Tennessee in 1990.

\section{DANIEL M. CHEN}

Daniel M. Chen is a Professor of Industrial and Engineering Technology at Central Michigan University. He has taught various courses in Mechanical Engineering Technology during the last fifteen years. Currently, near half of his teaching load is in CAD/CAM/CAE. Dr. Chen is a registered Professional Engineer in Michigan. He received

Proceedings of the 2001 American Society for Engineering Education Annual Conference \& Exposition Copyright (C) 2001, American Society for Engineering Education 
his Ph.D. in Mechanical Engineering from Kansas State University in 1984. He received his B.S. and M.S. in that same discipline from Taipei Institute of Technology and South Dakota School of Mines and Technology, respectively. 